Special issue of the 3rd International Conference on Computational and Experimental Science and Engineering (ICCESEN 2016)

\title{
Connection Between Smoking Statuses and Anger-Anger Style of the Health Services Vocational School Students
}

\begin{abstract}
A. SAY, A. AYAR AND D. ÇAKIR*
Sabuncuoğlu Şerefeddin Vocational School of Health Services, Amasya University, Amasya, Turkey

This study was carried out at Sabuncuoğlu Şerefeddin Vocational School of Health Services, Amasya University. In this study, the relationship between smoking habits and rage and anger of the Vocational School students was examined for identification purposes. Within the scope of this study, the survey was performed to reach 608 out of 822 students in 2015-2016. The youth socioeconomic factors influencing smoking, cultural characteristics, as well as peer influence, emulation, school failure, loneliness, alcohol and drug use, social students' range and anger along with psychological factors, such as stress were analyzed cross-sectionally. The demographic questionnaire used for the data collection, information about smoking habits and the anger-anger scale were used. The independent variables were age, gender, type of school, parents' educational level, parental occupational status, income, and income perception. The reasons for smoking initiation, trying, quitting and continuing to smoke of smokers and non-smokers and anger styles related to these reasons were compared. Consequently, in our study, the smoking habits of males have been found more pronounced when compared to females. However, no significant relationship was found between the smoking habits and the anger-anger style. The age of smoking initiation has been determined to be proportional to the beginning of adolescence. This study will shed light on possibilities of smoking prevention and will facilitate quitting of smoking.
\end{abstract}

DOI: $10.12693 /$ APhysPolA.132.783

PACS/topics: 42.62.Be

\section{Introduction}

Although it is more accurate to use the terms of tobacco addiction or tobacco harms, cigarette addiction and the harms of cigarettes are generally mentioned, since cigarette is a frequently used tobacco product [1]. Cigarette addiction is defined by the World Health Organization (WHO) as "regularly smoking a cigarette in a day". Furthermore, both the WHO and the International Classification of Diseases and Health Problems-10 (CDC-10) have addressed smoking as one of the disease classes [2].

One of the important emotional expressions, exhibited by young people at the university age, as well as in all other age groups, is anger. The form of expressing anger is important. If anger cannot be disclosed or expressed in appropriate ways, it may cause physical, psychological and social problems in a person [3]. Anger is an inborn emotional response, which develops during the first years of life, occurs very often during the daily life of a child or a young person. It is an extremely natural and universal reaction, given against unsatisfied requests, unintended consequences, and unmet expectations. It does not contain aggressiveness and violence, enriches the life, and is necessary for the survival of life [4].

It is stated that such factors as health status, gender, school success, relationships with the family and friends determine the form of expressing anger in individuals [5]. The purpose of this study is to investigate

*corresponding author; e-mail: demet.cakir@amasya.edu.tr college students' anger control levels, smoking, and the related factors. Students of health-related departments should be, first of all, healthy, from the biopsychosocial aspect, when it is considered that they will provide services for the protection and restoration of the health of individuals, families, and society, upon beginning their professional life.

Students, who cannot control their anger and cannot establish meaningful and satisfying relationships, experience several difficulties in fulfilling their responsibilities towards the individuals and/or relatives they serve, towards the society, colleagues and the health team members [6]. The determination of these problems during the training process, identification, and provision of the necessary support are quite important for the individual and professional development of the student. In this study, it was aimed to determine whether there is a relationship between the levels of expressing anger of the students, who participated in the study, and their smoking habits and demographic characteristics.

\section{Material and methods}

This study is a cross-sectional and descriptive study carried out on the students studying at Amasya University, Health Services Vocational High School in May of the 2015-2016 academic years, who had agreed to participate in the survey. 384 out of 822 students were reached. A multiple selection survey, consisting of 42 questions, was offered to the students. In the study, the data were obtained by using the survey method and anger expression style scale, which was developed by Butcher and Spielberger in 1983 and the validity and reliability studies of which were performed by Özer in our country in $1994[7,8]$. 
The scale is a four-point Likert-type scale. High control anger scores indicate that anger can be controlled or it is attempted to keep it under control. High anger-out scores indicate that anger cannot be controlled and is directed outwards or to other objects. High anger internal scores indicate that anger is transmitted inside, is not shared, is repressed and cannot be expressed verbally. SPSS 16.0 program package was used in the analysis of the data. The percentage, chi-square test and one-way analysis of variance (ANOVA) were used in the evaluation of the data. The Demographic Information Form and the Anger Expression Style Scale (AESS) were used.

\section{Results}

$248(64.6 \%)$ of the students who participated in the study were between the ages of 18-19 years, 117 (30.4\%) of them were between 20-21 years, and 19 (4.9\%) of them were 22 years and older. The average age of the students was $19.3 \pm 1.32(18-23+)$ years. $270(70.3 \%)$ of the students were female, and $113(29.4 \%)$ of them were male.

While $18.2 \%$ of the students lived with their families, $27.3 \%$ of them lived in the student house, and $54.4 \%$ of them lived in the dormitory. $54.1 \%$ of them declared their family income to be between 500-1500 Turkish Liras (TL), $31.7 \%$ of them declared it to be between 1501-2500 TL, and $14.1 \%$ of them declared it to be over $2500 \mathrm{TL}$. While $23.7 \%$ of the students said that they were smoking, $49.7 \%$ of them said that they have never smoked, $22.4 \%$ of them gave the answer of "I tried it but I did not smoke", and $4.2 \%$ of them gave the answer of "I used to smoke but I quit".

The ratio of male students who smoked was $50.9 \%$, and it was $12.2 \%$ for female students. While $4.7 \%$ of the mothers and $36.5 \%$ of the fathers were smoking in the families of the students, the ratio of the answer, that both were smoking, was $7.6 \%$. 9.4\% of the smoking students smoke more than 11 cigarettes in a day. The lowest score to be obtained from the anger expression style sub-scales was 8 , the highest score was 32 . The anger expression style scores of the students are presented in Table I.

TABLE I

The distribution of the students' anger expression style scale scores.

\begin{tabular}{c|c|c|c}
\hline \hline Subgroups & Min. & Max. & $\mathrm{X} \pm \mathrm{SD}$ \\
\hline Anger control & 9.00 & 32.00 & $21.64 \pm 5.04$ \\
Anger extroversion & 8.00 & 32.00 & $16.48 \pm 4.96$ \\
Anger introversion & 8.00 & 29.00 & $16.89 \pm 4.42$ \\
\hline
\end{tabular}

SD: Standard deviation; Min: Minimum; Max: Maximum.

Furthermore, a negative and positive significant relationship was found between anger introversion/anger control, anger control/anger extroversion.

TABLE II

Comparison of the anger expression styles and individual characteristics of the students.

\begin{tabular}{|c|c|c|c|c|}
\hline & & Anger control & Anger extroversion & Anger introversion \\
\hline & & $\mathrm{X} \pm \mathrm{SD}$ & $\mathrm{X} \pm \mathrm{SD}$ & $\mathrm{X} \pm \mathrm{SD}$ \\
\hline Cigarette & I have never smoked & $22.38 \pm 5.93$ & $15.53 \pm 4.62$ & $16.49 \pm 4.48$ \\
\hline & I tried but I did not smoke & $20.74 \pm 4.53$ & $16.98 \pm 4.92$ & $17.01 \pm 3.94$ \\
\hline & I used to smoke but I quit & $21.37 \pm 6.10$ & $16.25 \pm 5.07$ & $15.87 \pm 4.29$ \\
\hline & I'm still smoking & $21.00 \pm 4.96$ & $18.03 \pm 5.29$ & $17.81 \pm 4.63$ \\
\hline & & $p=0.38$ & $p<0.05^{*}$ & $p=0.09$ \\
\hline Other than tobacco & I certainly did not smoke & $21.67 \pm 5.08$ & $16.17 \pm 4.75$ & $16.61 \pm 4.28$ \\
\hline & I tried once & $21.50 \pm 4.62$ & $20.29 \pm 5.90$ & $19.83 \pm 4.72$ \\
\hline & I smoke $1-2$ times a year & $20.20 \pm 6.30$ & $19.40 \pm 5.50$ & $23.00 \pm 5.20$ \\
\hline & I smoke $3-5$ times a year & $22.50 \pm 2.12$ & $19.50 \pm 10.60$ & $16.00 \pm 1.41$ \\
\hline & I smoke $10+$ times a year & $\begin{array}{l}21.00 \\
p=0.97\end{array}$ & $\begin{array}{l}13.00 \\
p<0.05^{*}\end{array}$ & $\begin{array}{l}18.00 \\
p<0.05^{*}\end{array}$ \\
\hline
\end{tabular}

When the students' anger expression styles were compared with their individual characteristics, no statistical significance was found between their age, gender, place of birth, place of residence in Amasya, previous city center of their residence, income level of the family, occupational and educational status of the parents, families' social situations, status of participating in social activities and their anger expression styles. However, significant differences were found between anger extroversion and anger introversion by smoking, anger extroversion and anger introversion by the use of other substances (Table II).

\section{Conclusions}

In our study, the students' anger extroversion and anger introversion increased, but anger control decreased, and a statistically significant relationship was found when the students' anger expression styles related to the status of smoking, the use of alcohol and other substances 
were examined. Further studies should be carried out for providing rehabilitation aid necessary for the treatment of cigarette addiction.

\section{References}

[1] T. Demir, Sempozyum Dizisi 62, 231 (2008).

[2] WHO report on the global tobacco epidemic: implementing smoke-free environments, World Health Organization, Geneva 2009.

[3] T.M. Starner, R.M. Peters, J. School Nursing 20, 335 (2004).
[4] B. Albayrak, Y. Kutlu, Maltepe Üniversitesi Hemşirelik Bilim ve Sanatı Dergisi 2, 57 (2009).

[5] H. Yavuzer, Child and Crime, 10th ed., Remzi Kitabevi, İstanbul 2001 (in Turkish).

[6] N. Elkin, F. Karadağlı, Anadolu Kliniği 21, 64 (2016).

[7] J.N. Butcher, C.D. Spielberger, Advances in personality assessment, 1st ed., Routledge, New York 1983.

[8] K. Özer, Türk Psikoloji Dergisi 9, 12 (1994). 